\title{
Diffusion Coefficients and Phase Equilibria of the Cu-Zn Binary System Studied Using Diffusion Couples
}

\author{
Christopher M. Eastman Jr${ }^{1,2} \cdot$ Qiaofu Zhang ${ }^{1,3} \cdot$ Ji-Cheng Zhao ${ }^{1,4}$
}

Submitted: 11 May 2020/in revised form: 22 July 2020/Published online: 10 August 2020

(C) ASM International 2020

\begin{abstract}
The diffusion behavior and phase equilibria in the $\mathrm{Cu}-\mathrm{Zn}$ binary system were investigated using solidsolid and solid-liquid diffusion couples. Heat treatments at temperatures ranging from 100 to $750{ }^{\circ} \mathrm{C}$ were performed and the samples were examined using optical microscopy, energy dispersive $\mathrm{x}$-ray spectroscopy, and electron probe microanalysis to identify the phases and to obtain composition profiles. Solubility limits of both solid solution and intermetallic phases were then evaluated, and a forwardsimulation analysis (FSA) was applied to extract interdiffusion coefficients. The composition profiles from Hoxha et al. were also re-analyzed using FSA to obtain more reliable diffusion coefficient data without the assumption of constant diffusion coefficients for the intermetallic phases. A comprehensive assessment of the interdiffusion coefficients in three intermetallic phases of the $\mathrm{Cu}-\mathrm{Zn}$ system was performed based on the results from the current study as well as those in the literature. Activation energies and Arrhenius pre-factors were evaluated for each phase as a function of composition. The fitted equations based on the comprehensive assessment have the capabilities of computing the interdiffusion coefficients of each of the phases at a given composition and temperature. Suggested modifications to the $\mathrm{Cu}-\mathrm{Zn}$ binary phase diagram were
\end{abstract}

Ji-Cheng Zhao

jczhao@umd.edu

1 Department of Materials Science and Engineering, The Ohio State University, Columbus, OH 43210

2 TimkenSteel Corporation, Canton, OH 44706

3 QuesTek Innovations LLC, 1820 Ridge Avenue, Evanston, IL 60201

4 Department of Materials Science and Engineering, University of Maryland, College Park, MD 20742 presented based on the new experimental information gathered from the present study. A clear explanation is provided for the puzzling low $\mathrm{Zn}$ concentrations often observed in the $\mathrm{Cu}$-rich fcc phase of $\mathrm{Cu}-\mathrm{Zn}$ diffusion couples in comparison with the expected high solubility values based on the equilibrium $\mathrm{Cu}-\mathrm{Zn}$ phase diagram.

Keywords $\mathrm{Cu}$ - $\mathrm{Zn}$ - diffusion couples · interdiffusion coefficients $\cdot$ phase diagram

\section{Introduction}

Zinc is one of the most widely used alloying elements in $\mathrm{Cu}$ alloys, thus diffusion coefficients in both the solid solution and intermetallic phases in the $\mathrm{Cu}-\mathrm{Zn}$ system and the $\mathrm{Cu}-\mathrm{Zn}$ binary phase diagram are essential for understanding the kinetics and phase stability of $\mathrm{Cu}$ alloys. Even though several research groups have studied this important binary system over the years, ${ }^{[1-16]}$ there are still discrepancies and lack of systematic data for the diffusion coefficients of various phases. The aim of this study is to develop a more comprehensive picture of the diffusion behavior in the $\mathrm{Cu}-\mathrm{Zn}$ system by performing diffusion experiments across a wide range of temperatures and by assessing experimental results from the literature together with the new data from the current study. Additional phase equilibrium data from the diffusion experiments will also be reported assuming local equilibrium at the phase interfaces.

One of the most careful assessments of the experimentally measured phase diagram for the $\mathrm{Cu}-\mathrm{Zn}$ binary system is provided by Miodownik ${ }^{[14]}$ as shown in Fig. 1, which will be used to check the phase formation in various 
Fig. $1 \mathrm{Cu}-\mathrm{Zn}$ binary phase diagram as reported in the ASM Alloy Phase Diagrams Database ${ }^{[17]}$ based on the assessment of Miodownik. ${ }^{[14]}$ The red dots and dashed lines represent suggested changes to the phase boundaries based on experimental results obtained from the present study

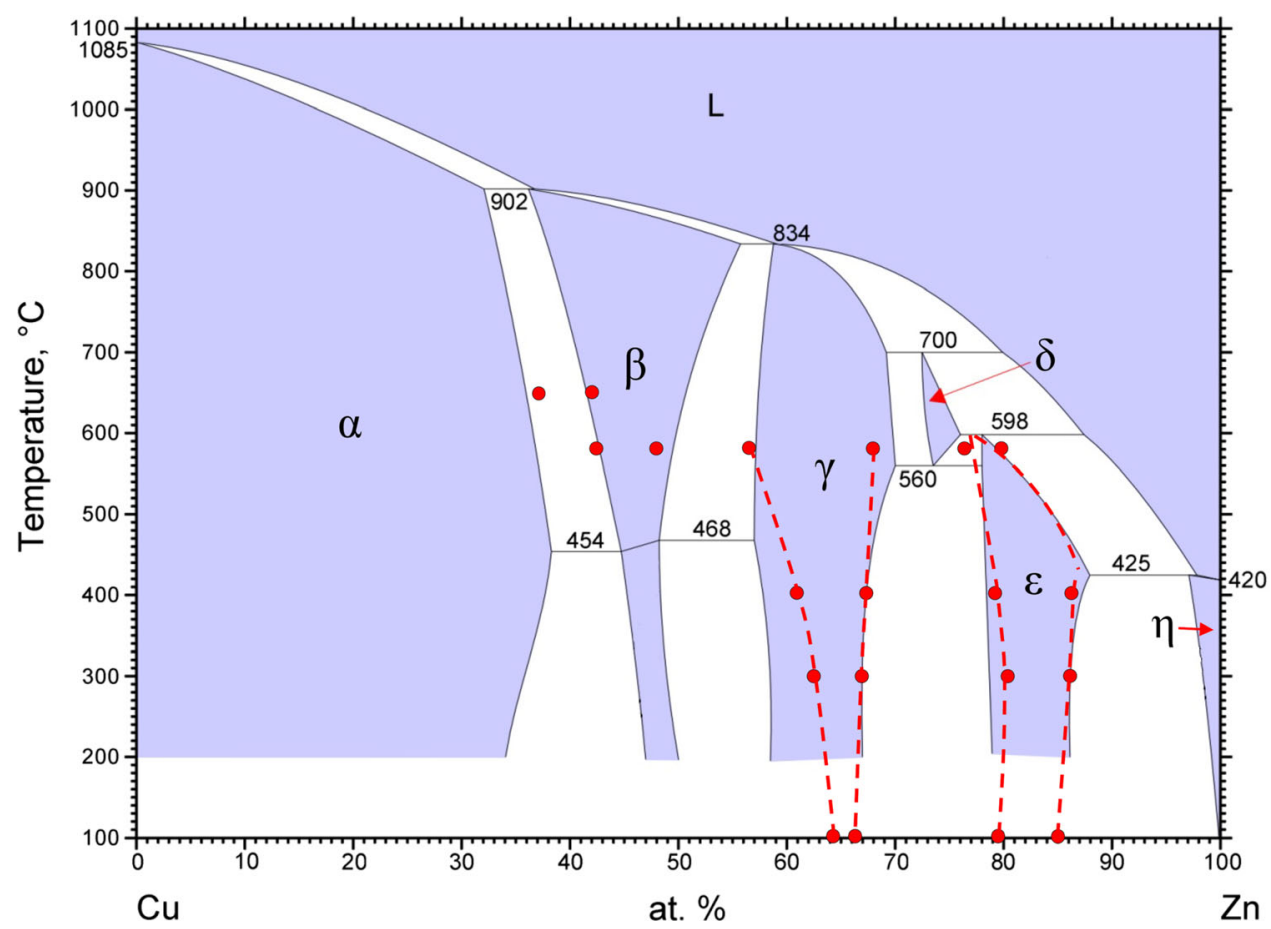

diffusion couples based on the composition. The phases are sequentially named from $\alpha$ to $\eta$ from $\mathrm{Cu}$ to $\mathrm{Zn}$ to be consistent with the literature convention.

Hoxha et al. made diffusion couples of pure $\mathrm{Cu}$ and pure $\mathrm{Zn}$ and heat treated them for multiple annealing times ranging from 1 to $32 \mathrm{~h}$ at all four temperatures, 250, 300, 350 , and $380{ }^{\circ} \mathrm{C} .{ }^{[15,16]}$ They measured concentration profiles using electron-probe microanalysis (EPMA) and used those from the long annealing durations to calculate parabolic rate constants which were then converted into interdiffusion coefficients for the intermetallic phases. This approach is a simplistic calculation that can only yield an average diffusion coefficient for a given phase at a given temperature, assuming the diffusion coefficients are independent of composition which is not a good assumption for some of the intermetallic phases that show very strong composition-dependency.

The forward simulation analysis (FSA) developed by Zhang and Zhao can take a full composition profile that ranges across the full spectrum of the phases in a binary phase diagram and extract the diffusion coefficient at any composition in the composition profile, including reliable impurity diffusion coefficients at both ends. ${ }^{[18]}$ The overall process of FSA includes the following steps: (a) the traditional methods (Wagner, Boltzmann-Matano and SauerFreise) ${ }^{[19-21]}$ are employed to extract the interdiffusion coefficients for each phase from a smoothed experimental composition profile; (b) a composition-dependent interdiffusion coefficient function (e.g., constant, linear or parabolic) is assumed based on the trends of the interdiffusion coefficients for each phase from the traditional analyses; (c) Fick's laws of diffusion are applied using the assumed diffusion coefficients with adjustable parameters in the function to create a simulated concentration profile; and (d) the interdiffusion coefficient functions are adjusted based on a comparison between the experimental and simulated concentration profiles with the objective of minimizing differences between the profiles. The final step is repeated multiple times until the two profiles agree with each other with a minimal difference. ${ }^{[22]}$ FSA reports the best diffusion coefficient functions across the complete compositional range of the experimental profile, which are taken as the extracted diffusion coefficients. FSA has been successfully applied to a wide range of systems to obtain both interdiffusion and impurity diffusion coefficients. $^{\text {[18, 22-29] }}$

The original diffusion composition profiles of all four temperatures $\left(250,300,350\right.$, and $\left.380{ }^{\circ} \mathrm{C}\right)$ were kindly provided to us by Hoxha et al. FSA was applied to these profiles to obtain both impurity and interdiffusion coefficients of the solid solution and intermetallic phases without assuming constant diffusion coefficients for the intermetallic phases. In this study, the molar volume variation in each phase in the $\mathrm{Cu}-\mathrm{Zn}$ system is not considered and it is assumed constant. The diffusion coefficients reported by all other groups are taken as reported without re-analysis using FSA since the original diffusion profiles from these groups were unavailable. The temperature range in the current study was expanded to a range of $100-750{ }^{\circ} \mathrm{C}$ using both solid-solid and solid-liquid diffusion couples. 


\section{Experimental Procedure}

A variety of pure $\mathrm{Cu}-$ pure $\mathrm{Zn}$ diffusion couples were used to conduct diffusion experiments at a wide range of temperatures (Table 1). Simple solid-solid diffusion couples made up of pure $\mathrm{Cu}$ and pure $\mathrm{Zn}$ were employed for 100 , 300 , and $400{ }^{\circ} \mathrm{C}$, and were heat treated in a horizontal tube furnace. A heat treatment at $580{ }^{\circ} \mathrm{C}$ was performed using a solid $\mathrm{Cu}$ cone dipped inside a liquid $\mathrm{Zn}$ bath in an alumina crucible. Heat treatments at both 650 and $750{ }^{\circ} \mathrm{C}$ employed transient liquid phase (TLP) diffusion couples consisting of two copper plates sandwiched with a thin sheet of zinc that was pressed to about $1 \mathrm{~mm}$ in thickness. Additional solidliquid diffusion couples were heat treated at temperatures between 570 and $690{ }^{\circ} \mathrm{C}$ to study the phase boundaries of the high temperature $\delta$ phase, but these couples were not used to calculate diffusion coefficients. All solid-solid diffusion couples and TLP diffusion couples were mechanically joined using a vertical press under $200 \mathrm{kN}$ force. These diffusion couples together with the solidliquid samples were encapsulated in quartz tubes backfilled with $0.2 \mathrm{~atm}$ argon gas to protect them from oxidation during diffusion heat treatments. After the heat treatments, the diffusion couples were water quenched by breaking the quartz tubes to let the samples drop into a tank of water. The diffusion coefficient data at $400{ }^{\circ} \mathrm{C}$ are less reliable than other temperatures due to the very short diffusion anneal time $(4 \mathrm{~h})$.

Following the heat treatments, EPMA was performed to measure the resulting composition profiles (e.g., Figure 2). From each composition profile, the equilibrium tie-line compositions between single phase regions were extracted based on local equilibrium at the phase interfaces as manifested as discontinuities/jumps in the composition profiles, which provide the solubility limits of the relevant phases at the respective heat treatment temperature. FSA was then applied to most of the composition profiles obtained from the present study, as well as those from
Hoxha et al., to obtain the interdiffusion coefficients across the compositional ranges in each single-phase region present in the profile. By plotting the interdiffusion coeffi-
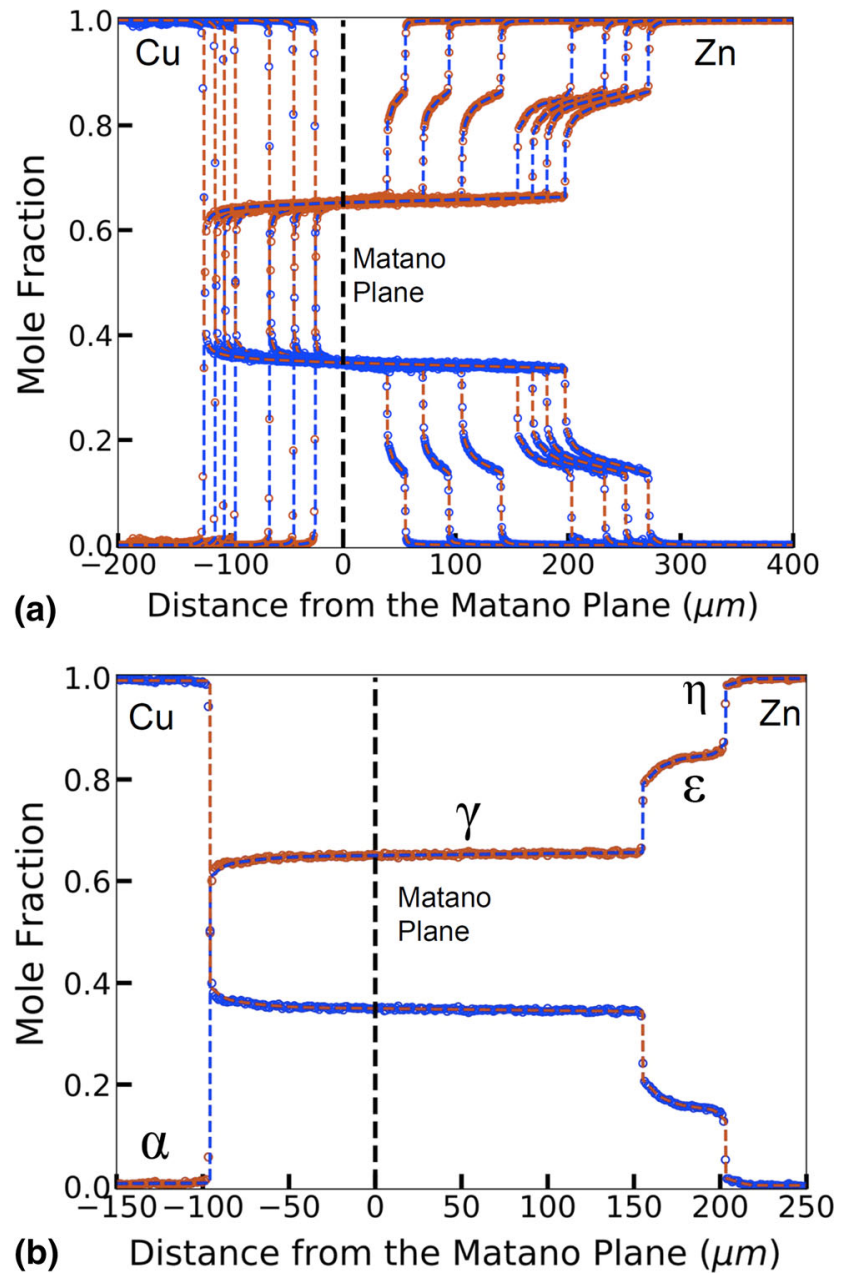

Fig. 2 (a) All composition profile data obtained by Hoxha et al. at $300{ }^{\circ} \mathrm{C}$ with an annealing time of $1,4,9,16,25,28$, and $32 \mathrm{~h}^{[15]}$; and (b) Composition profile from a $\mathrm{Cu}-\mathrm{Zn}$ (pure to pure) diffusion couple after being annealed at $300{ }^{\circ} \mathrm{C}$ for $28 \mathrm{~h}$
Table 1 All heat treatment temperatures and durations together with the respective diffusion couple types

\begin{tabular}{lcl}
\hline Temperature $/{ }^{\circ} \mathrm{C}$ & Duration $/ \mathrm{h}$ & \multicolumn{1}{c}{ Diffusion couple type } \\
\hline 100 & 766 & Solid-solid diffusion couple \\
300 & 28 & Solid-solid diffusion couple \\
400 & 4 & Solid-solid diffusion couple \\
570 & 5.1 & Solid-liquid diffusion couple \\
580 & 5 & Solid-liquid diffusion couple \\
590 & 3.5 & Solid-liquid diffusion couple \\
610 & 4 & Solid-liquid diffusion couple \\
650 & 10 & Transient liquid phase diffusion couple \\
650 & 4 & Solid-liquid diffusion couple \\
690 & 3 & Solid-liquid diffusion couple \\
750 & 10 & Transient liquid phase diffusion couple
\end{tabular}


cients at a given composition against the inverse temperature $(1 / \mathrm{T})$, the activation energy and Arrhenius prefactor were obtained for that composition. The activation energy and prefactor were calculated and plotted against composition for the $\gamma$ and $\varepsilon$ intermetallic phases, and the fcc $\alpha-\mathrm{Cu}$ solid solution phase. The interdiffusion coefficients and activation energies of the $\beta$ intermetallic phase and the hcp $\eta$ - Zn solid solution phase were calculated as constants (independent of composition) at most heat treatment temperatures due to the minimal amount of phase formation during the respective heat treatments and the narrow composition ranges for these two phases.

\section{Phase Equilibria}

As mentioned in the Introduction section, the full $\mathrm{Cu}-\mathrm{Zn}$ binary phase diagram reported in the ASM Phase Diagram Database ${ }^{[17]}$ based on the assessment of Miodownik $^{[14]}$ (Fig. 1) was used as the base for comparison since it includes temperatures as low as $200{ }^{\circ} \mathrm{C}$. However, it should be noted that in the original assessment by Miodownik ${ }^{[14]}$ the phase boundaries below $300{ }^{\circ} \mathrm{C}$ are indicated as estimated. Other assessments of the experimental $\mathrm{Cu}-\mathrm{Zn}$ phase diagram focused on temperatures above $500{ }^{\circ} \mathrm{C}$ or on specific composition ranges that are not comprehensive enough for comparison with our results that cover the entire composition range (essentially pure to pure) and a wide range of temperatures $\left(100-750^{\circ} \mathrm{C}\right)$.

Phase boundaries of the $\beta, \gamma$ and $\varepsilon$ intermetallic phases at $100{ }^{\circ} \mathrm{C}, 300{ }^{\circ} \mathrm{C}$, and $400{ }^{\circ} \mathrm{C}$ were measured assuming local equilibrium at the phase interfaces in the corresponding diffusion couples. At $580{ }^{\circ} \mathrm{C}$, the phase boundaries of the $\beta, \gamma$ and $\varepsilon$ intermetallic phases were clear, however, due to the presence of a two-phase region, the phase boundaries of the high temperature intermetallic $\delta$ phase were more difficult to identify (Fig. 3, 4). Very limited Zn concentrations were observed in the fcc $\alpha-\mathrm{Cu}$ phase at these four temperatures $\left(100{ }^{\circ} \mathrm{C}, 300{ }^{\circ} \mathrm{C}, 400{ }^{\circ} \mathrm{C}\right.$ and $\left.580{ }^{\circ} \mathrm{C}\right)$, which were significantly below the solubility of $\mathrm{Zn}$ in the fcc $\alpha$ $\mathrm{Cu}$ phase according to the phase diagram in Fig. 1. The same phenomenon can be clearly seen in diffusion profiles reported by others, e.g., Figure 2(a) from Hoxha et al., and will be explained later. The TLP experiments at 650 and $750{ }^{\circ} \mathrm{C}$ were the only temperatures at which significant width of the $\mathrm{Zn}$-containing fcc $\alpha$-Cu phase was observed, and the maximum $\mathrm{Zn}$ concentration in the fcc $\alpha-\mathrm{Cu}$ phase at $650{ }^{\circ} \mathrm{C}$ started to match the $\mathrm{Zn}$ solubility expected from the phase diagram. The $\mathrm{Cu}$-rich phase boundary of the $\beta$ phase was also measured at $650{ }^{\circ} \mathrm{C}$.

Additional solid-liquid diffusion couple experiments were conducted at temperatures between 570 and $690{ }^{\circ} \mathrm{C}$ in an attempt to better define the phase boundaries of the high

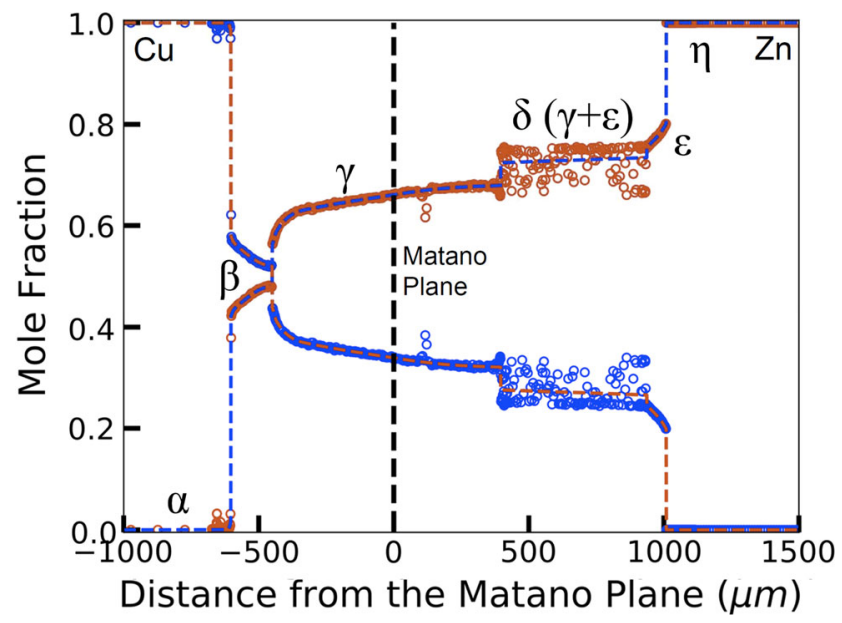

Fig. 3 Composition profile obtained from a solid-liquid diffusion couple that was annealed at $580{ }^{\circ} \mathrm{C}$ for $5 \mathrm{~h}$. The presence of the twophase region where the high temperature intermetallic $\delta$ phase would be expected is evident by the scatter in the EPMA compositions. The two-phase mixture is the result of eutectoid decomposition of the $\delta$ phase to the $\gamma$ and $\varepsilon$ phases during cooling from $580{ }^{\circ} \mathrm{C}$ to ambient temperature

temperature intermetallic $\delta$ phase (Fig. 5). In each case, even with a rapid quench of the sample into water, a twophase region formed at compositions between the $\gamma$ and $\varepsilon$ intermetallic phases. It is believed that the two-phase region is the result of eutectoid decomposition during cooling of the intermetallic $\delta$ phase. Because the phase decomposed even at high cooling rates during a water quench, it suggests that the eutectoid decomposition kinetics of the $\delta$ phase are quite high.

Different two-phase morphologies were evident in the $690{ }^{\circ} \mathrm{C}$-annealed solid-liquid diffusion couple. The region adjacent to the $\gamma$ single-phase on the left of Fig. 5 exhibited large $\gamma$ precipitates embedded in a finely-featured twophase mixture which extended all the way to the right-hand side end of the supposedly $\delta$ phase region. The coarse, irregular two-phase region on the far right-hand side of Fig. 5 is the solidified liquid-phase region from $690^{\circ} \mathrm{C}$. It is believed that the large $\gamma$ precipitates started to form in the $\delta$ matrix first as the $\mathrm{Cu}$-rich side of the $\delta$ phase crossed the $(\gamma+\delta) / \delta$ phase boundary upon cooling from $690{ }^{\circ} \mathrm{C}$. Upon further cooling past the eutectoid temperature, the remaining $\delta$ phase matrix underwent eutectoid decomposition forming the fine $(\gamma+\varepsilon)$ two-phase microconstituents. The $\mathrm{Zn}$-rich side of the $\delta$ phase appears to only undergo the eutectoid decomposition into the fine $(\gamma+\varepsilon)$ two-phase region likely due to the fact that the composition of the $\mathrm{Zn}$-rich side of the $\delta$ phase at $690{ }^{\circ} \mathrm{C}$ coincides with the eutectoid composition of $\delta \rightarrow \gamma+\varepsilon$. Due to the rapid decomposition of the high-temperature $\delta$ phase, the solidliquid diffusion couple experiments were unable to yield more phase equilibrium data for the $\delta$ phase as intended. 
Fig. 4 Backscattered electron image of the diffusion zone from the conical solid-liquid diffusion sample after being heat treated at $580{ }^{\circ} \mathrm{C}$ for $5 \mathrm{~h}$. A higher magnification image on the left shows the interfaces between the solidified liquid, the $\varepsilon$ intermetallic phase, and a two-phase $(\gamma$ and $\varepsilon)$ during cooling microstructure that formed
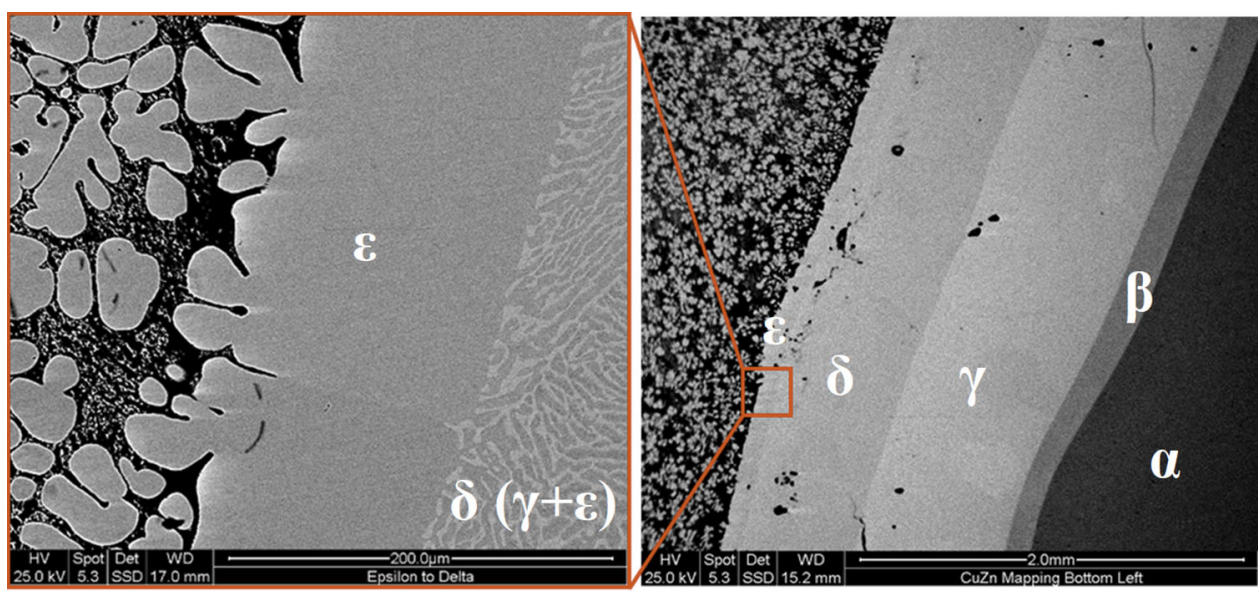

Fig. 5 Optical micrographs of the $\mathrm{Zn}$-rich diffusion zone from a solid-liquid couple after being heat treated at $690{ }^{\circ} \mathrm{C}$ for $3 \mathrm{~h}$

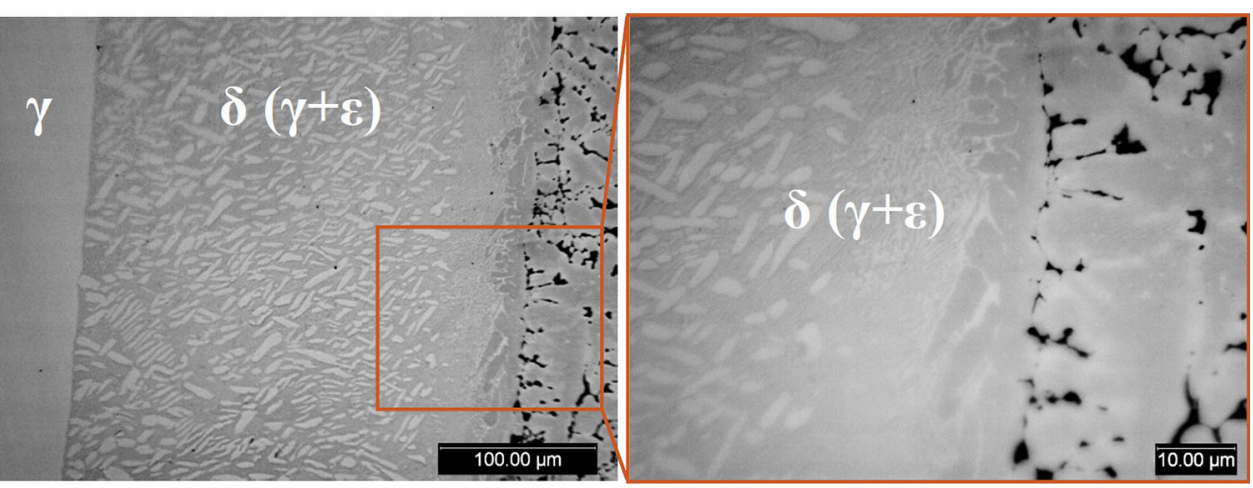

All the phase boundary data obtained from the current study assuming local equilibrium are designated as red dots in Fig. 1 in comparison with the $\mathrm{Cu}-\mathrm{Zn}$ phase diagram assessed by Miodownik. The data are also tabulated in Table 2. While most of our experimental data agree with the phase diagram, the $\gamma$ phase region narrows significantly with decreasing temperature. We believe our data are reliable for this phase and should be used to revise the $\mathrm{Cu}$ $\mathrm{Zn}$ binary phase diagram in the future.

As will be explained in more detail in the subsequent section, the low $\mathrm{Zn}$ concentrations in $\alpha-\mathrm{Cu}$ observed in our EMPA data, inconsistent with the phase diagram, are due to extremely low diffusion coefficients in this phase at low temperatures, resulting in an extremely thin layer of this phase with very steep gradients that are beyond the spatial resolution of EPMA. Such results were observed up to $580{ }^{\circ} \mathrm{C}$ at which the $\mathrm{Zn}$ solubility in the $\alpha$-Cu phase could still not be obtained. The $\mathrm{Cu}$-rich boundary of the $\beta$ phase could be reliably evaluated and reported since its composition gradient is very shallow.

\section{Interdiffusion Coefficients}

Interdiffusion coefficients were extracted using FSA from all the diffusion profiles provided to us by Hoxha et al. as well as the diffusion profiles obtained from the present study. Examples of the diffusion coefficients for various phases extracted from the $380{ }^{\circ} \mathrm{C}$ diffusion couples made by Hoxha et al. at six different diffusion annealing durations are shown in Fig. 6. The extracted diffusion coefficients from different annealing times are quite consistent, except for the fcc $\alpha$-Cu solid solution for which the diffusion coefficients at this temperature should not be trusted due to inadequate EPMA spatial resolution. The interdiffusion coefficients reported in subsequent figures are the values from the longest heat treatment duration ( $32 \mathrm{~h}$ ) at the respective temperatures investigated by Hoxha et al. One can clearly see that the diffusion coefficients for both the $\gamma$ phase and the $\varepsilon$ phase are very strongly compositiondependent, varying for about two orders of magnitude across a narrow composition range for the $\gamma$ phase and for about an order of magnitude for the $\varepsilon$ phase, Fig. 6 .

The interdiffusion coefficients will be presented subsequently for each of the single-phase regions in the $\mathrm{Cu}-\mathrm{Zn}$ binary system, starting with the fcc $\alpha-\mathrm{Cu}$ solid solution phase, followed by phases of increasing $\mathrm{Zn}$ content. 
Table 2 Phase boundary data obtained from solid-solid and solidliquid diffusion couple experiments

\begin{tabular}{lcc}
\hline Phase boundary & Temperature/ ${ }^{\circ} \mathrm{C}$ & at. \% $\mathrm{Zn}$ \\
\hline$\alpha / \alpha+\beta$ & 650 & 37.1 \\
$\alpha+\beta / \beta$ & 580 & 42.6 \\
$\alpha+\beta / \beta$ & 650 & 42.1 \\
$\beta / \beta+\gamma$ & 580 & 48.0 \\
$\beta+\gamma / \gamma$ & 100 & 64.6 \\
$\beta+\gamma / \gamma$ & 300 & 62.8 \\
$\beta+\gamma / \gamma$ & 400 & 61.0 \\
$\beta+\gamma / \gamma$ & 580 & 56.5 \\
$\gamma / \gamma+\varepsilon$ & 100 & 66.4 \\
$\gamma / \gamma+\varepsilon$ & 300 & 67.0 \\
$\gamma / \gamma+\varepsilon$ & 400 & 67.4 \\
$\gamma / \gamma+\delta$ & 580 & 68.1 \\
$\delta+\varepsilon / \varepsilon$ & 580 & 76.0 \\
$\gamma+\varepsilon / \varepsilon$ & 100 & 79.6 \\
$\gamma+\varepsilon / \varepsilon$ & 300 & 80.5 \\
$\gamma+\varepsilon / \varepsilon$ & 400 & 79.2 \\
$\varepsilon / \varepsilon+\eta$ & 100 & 85.2 \\
$\varepsilon / \varepsilon+\eta$ & 300 & 86.2 \\
$\varepsilon / \varepsilon+\eta$ & 400 & 86.4 \\
$\varepsilon / \varepsilon+\mathrm{L}$ & 580 & 79.8 \\
\hline
\end{tabular}

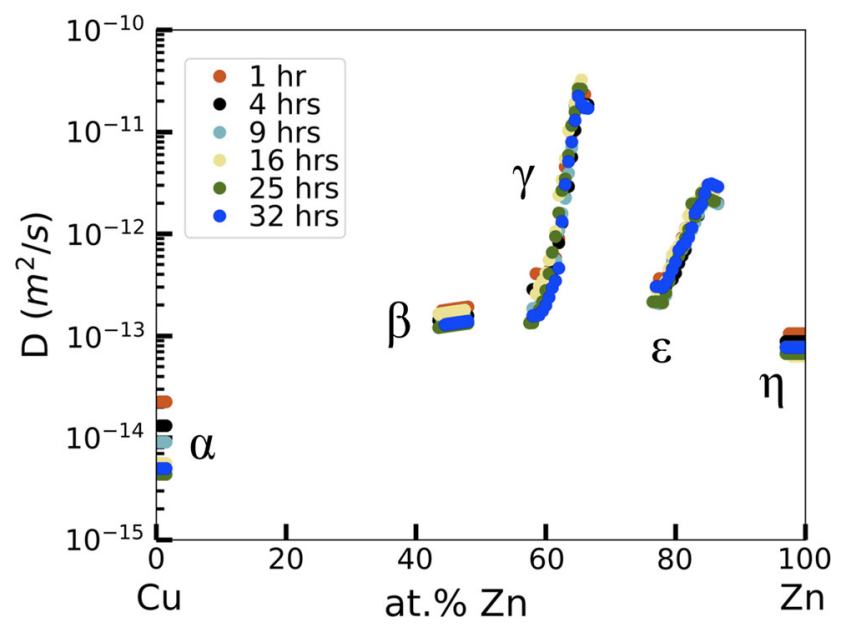

Fig. 6 Interdiffusion coefficients extracted using FSA from the composition profiles of $\mathrm{Cu}-\mathrm{Zn}$ diffusion couples made by Hoxha et al. that were annealed at $380{ }^{\circ} \mathrm{C}$ for six different durations. The diffusion coefficients were obtained for each of the phases as a function of composition without assuming constant diffusion coefficients for the intermetallic phases

Even though the transient liquid phase couples were not infinite diffusion couples, the interdiffusion coefficients in the solid phases in these samples could still be extracted using FSA, as already demonstrated in previous

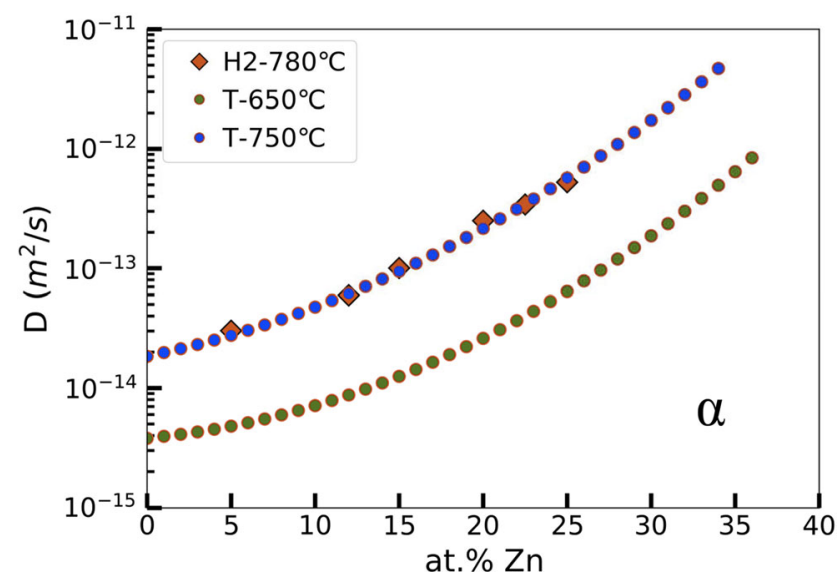

Fig. 7 Interdiffusion coefficients obtained from this study for the fcc $\alpha-\mathrm{Cu}$ phase extracted from the transient liquid phase diffusion couples that were diffusion annealed at $650{ }^{\circ} \mathrm{C}$ and $750{ }^{\circ} \mathrm{C}$ (Designated as $\mathrm{T}-650{ }^{\circ} \mathrm{C}$ and $\mathrm{T}-750{ }^{\circ} \mathrm{C}$ ). Interdiffusion coefficients at $780{ }^{\circ} \mathrm{C}$ reported by Horne and Mehl, ${ }^{[1]]}$ designated as $\mathrm{H} 2-780{ }^{\circ} \mathrm{C}$, are also included for comparison

studies. ${ }^{[25,28]}$ The extracted interdiffusion coefficients are shown in Fig. 7. Most of the interdiffusion coefficients available in the literature for the $\alpha-\mathrm{Cu}$ solid solution phase are consistent, but are limited to temperatures higher than $750{ }^{\circ} \mathrm{C} .{ }^{[7,10,11]}$ The interdiffusion coefficients obtained from the transient liquid phase diffusion couples annealed at 650 and $750{ }^{\circ} \mathrm{C}$ follow the same trend as the high temperature data from the literature as shown in Fig. 7. There is a slight difference since our data at $750{ }^{\circ} \mathrm{C}$ agree with the $780{ }^{\circ} \mathrm{C}$ data from Horne and Mehl, ${ }^{[11]}$ with a $30{ }^{\circ} \mathrm{C}$ temperature difference. Our data at both $650{ }^{\circ} \mathrm{C}$ and $750{ }^{\circ} \mathrm{C}$ are the only reliable experimental results from the current study since among all the temperatures we studied, only at these two temperatures the concentration profiles of $\mathrm{Zn}$ in $\alpha-\mathrm{Cu}$ are measurable and the $\mathrm{Zn}$ solubility values are consistent with the $\mathrm{Cu}-\mathrm{Zn}$ phase diagram. At temperatures $\leq 580{ }^{\circ} \mathrm{C}$, the observed maximum $\mathrm{Zn}$ concentrations in the fcc $\alpha-\mathrm{Cu}$ phase were significantly below the solubility values in the binary $\mathrm{Cu}-\mathrm{Zn}$ phase diagram. Therefore, the interdiffusion coefficients in the fcc $\alpha$-Cu phase below $580{ }^{\circ} \mathrm{C}$ are not considered reliable, and will not be reported here; as further discussed in Section 6.

Interdiffusion coefficients of the $\beta$ intermetallic phase reported by Sørensen and Maahn ${ }^{[5]}$ are consistent with the results reported by Funamizu and Watanabe ${ }^{[3,4]}$; whereas the $\sim 600^{\circ} \mathrm{C}$ results from Ugaste and Pimenov were close to the $\sim 550{ }^{\circ} \mathrm{C}$ results from the other two groups, ${ }^{[13]}$ as shown in Fig. 8, which collected all the available diffusion data for the $\beta$ phase. Results from this study are more consistent with the data from Sørensen and Maahn, and Funamizu and Watanabe. Overall the variation of results is about an order of magnitude, which is often the range of 


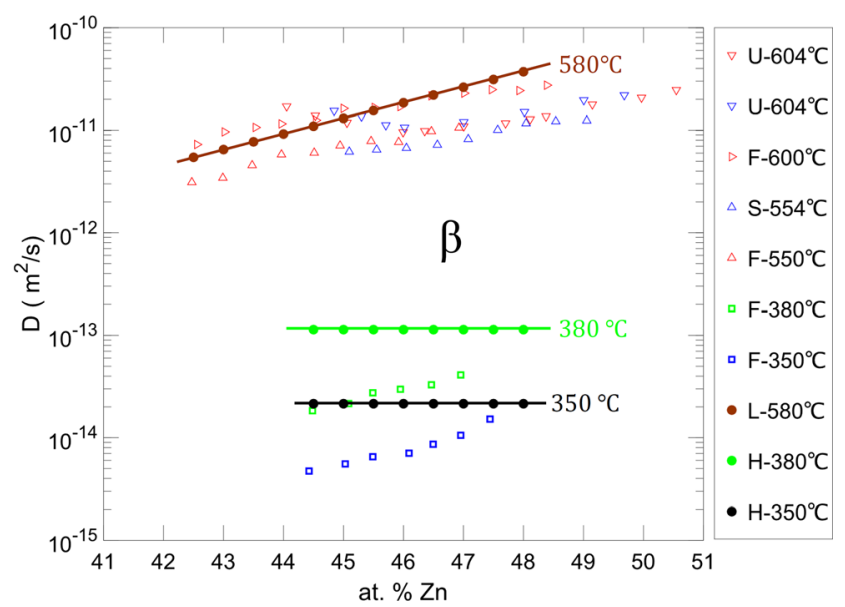

Fig. 8 All interdiffusion coefficients obtained for the $\beta$ intermetallic phase together with those from the literature.$^{[3-5,12,13,15]} \mathrm{U}$ : Ugaste and Pimenov; S: Sørensen and Maahn; F: Funamizu and Watanabe; L: Liquid-solid diffusion couple (This study); and H: FSA of Hoxha et al's diffusion profiles (This study)

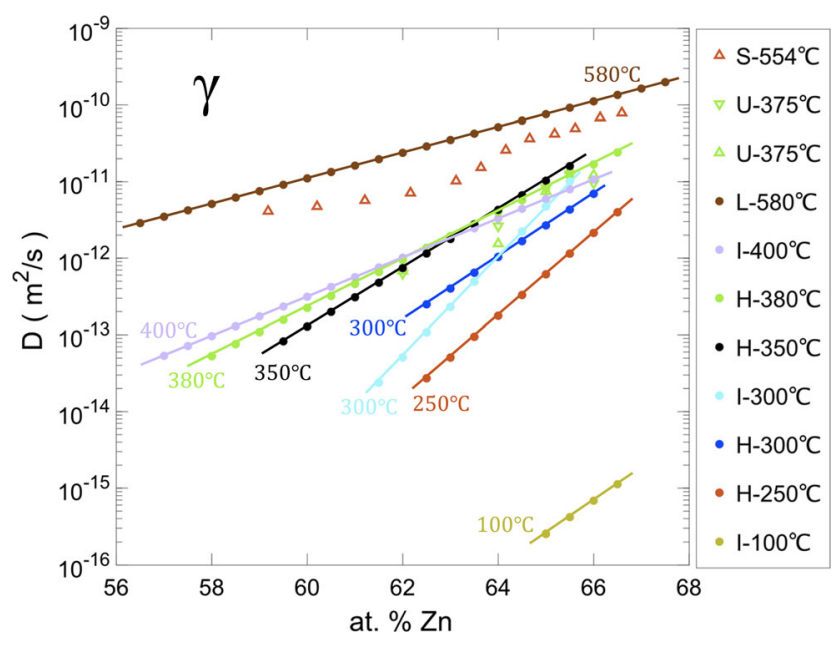

Fig. 9 All interdiffusion coefficients obtained for the $\gamma$ intermetallic phase together with those from the literature. ${ }^{[5,12,13,15]} \mathrm{U}$ : Ugaste and Pimenov; S: Sørensen and Maahn; L: Liquid-solid diffusion couple (This study); H: FSA of Hoxha et al's diffusion profiles (This study); and I: Infinite (pure to pure) $\mathrm{Cu}-\mathrm{Zn}$ diffusion couple (This study)

scattering of diffusion coefficients from different measurements.

Sørensen and Maahn, and Ugaste and Pimenov also obtained diffusion coefficients across the $\gamma$ intermetallic phase. Results obtained from this study agree well with all the data from the literature, showing a very strong increase of diffusion coefficients with increasing $\mathrm{Zn}$ concentration, Fig. 9.

Funamizu and Watanabe also obtained the interdiffusion coefficients in the $\varepsilon$ intermetallic phase at 6 temperatures between 250 and $400{ }^{\circ} \mathrm{C}$, Fig. 10. Ugaste and Pimenov

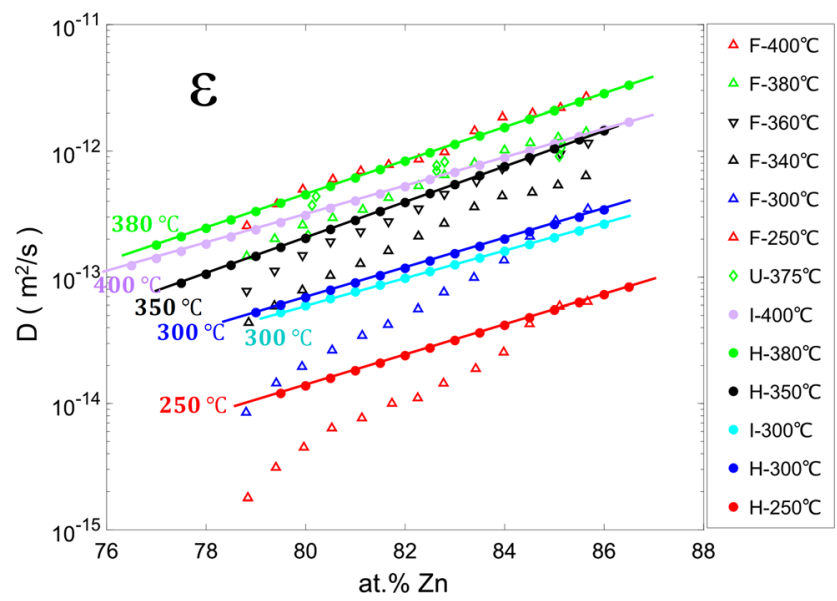

Fig. 10 All interdiffusion coefficients obtained for the $\varepsilon$ intermetallic phase together with those from the literature. ${ }^{[3,4,12,13,15]} \mathrm{U}$ : Ugaste and Pimenov; F: Funamizu and Watanabe, L: Liquid-solid diffusion couple (This study); H: FSA of Hoxha et al's diffusion profiles (This study); and I: Infinite (pure to pure) $\mathrm{Cu}-\mathrm{Zn}$ diffusion couple (This study)

reported data at $375{ }^{\circ} \mathrm{C}$ only. Diffusion coefficients obtained from the current study at multiple temperatures are also included in Fig. 10, which shows good overall agreement with those from the literature and a strong increasing trend as the $\mathrm{Zn}$ concentration in the phase increases. The data at lower temperatures $\left(250{ }^{\circ} \mathrm{C}\right.$ and $300{ }^{\circ} \mathrm{C}$ ) have more variations than the high temperature data; again, up to about an order of magnitude.

Diffusion data in the high temperature $\delta$ phase could not be found in the literature. An attempt was made to obtain the interdiffusion coefficients for this phase despite its eutectoid decomposition into the $\gamma+\varepsilon$ two-phase region during cooling. The composition profile used to calculate the diffusivity profile of the $\delta$ phase was created using a moving average of the composition across the two-phase microstructure of the sample after the $580{ }^{\circ} \mathrm{C}$ diffusion annealing. Due to the narrow compositional range of the $\delta$ phase at $580{ }^{\circ} \mathrm{C}$, the interdiffusion coefficient was calculated as a constant and yielded a value of $3.7 \times 10^{-10} \mathrm{~m}^{2} / \mathrm{s}$ at $580{ }^{\circ} \mathrm{C}$.

No interdiffusion coefficients could be found in the literature for the hcp $\eta-\mathrm{Zn}$ solid solution phase either. Similar to the fcc $\alpha-\mathrm{Cu}$ phase, the hcp $\eta$-Zn phase was too thin in most of our diffusion couples to be reliably measured by EPMA. The impurity diffusion coefficients of $\mathrm{Cu}$ in hep $\eta$ $\mathrm{Zn}$ reported by Batra and Huntington (Fig. 11) ${ }^{[1,2]}$ are recommended for diffusion simulations involving the hep $\eta$ - Zn phase, with an Arrhenius equation of $D_{C u i n Z n}=$ $2.1 \times 10^{-4} e^{-124580 / R T}\left(\mathrm{~m}^{2} / \mathrm{s}\right)$ by averaging the $\mathrm{D}_{\|}$and $\mathrm{D}_{\perp}$ according to a practice of $D_{\text {average }}=\frac{1}{3} D_{\|}+\frac{2}{3} D_{\perp}$ for the estimated diffusion coefficients of polycrystalline samples. ${ }^{[30]}$ Because of the narrow compositional range of the 


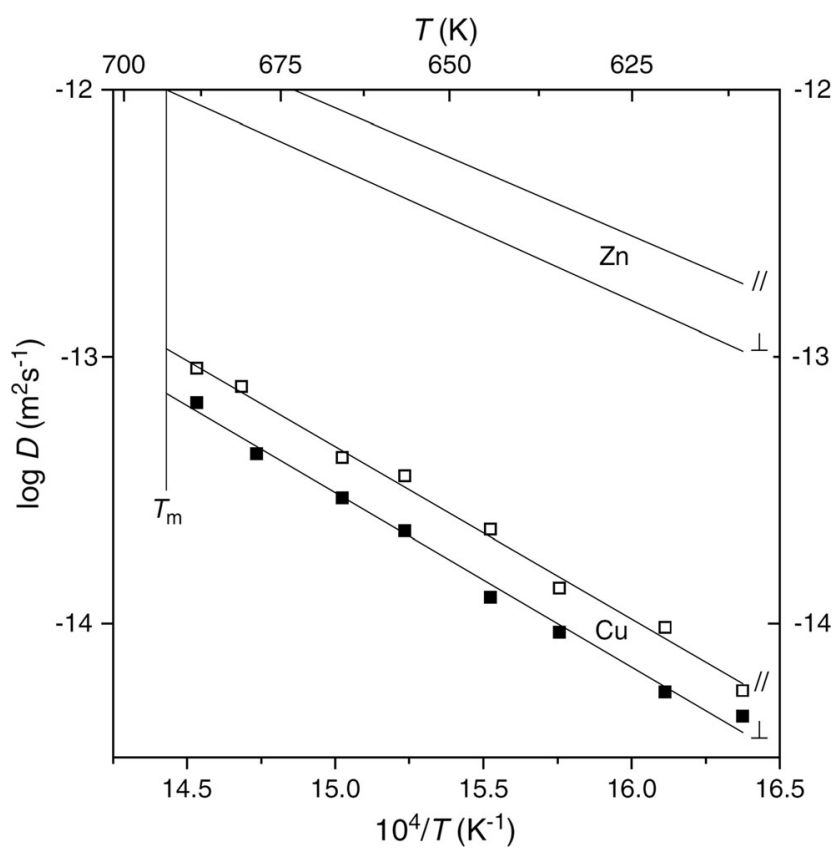

Fig. 11 Impurity diffusion coefficients of $\mathrm{Cu}$ in pure $\mathrm{Zn}$ at various temperatures in comparison with the self-diffusion coefficients of $\mathrm{Zn}^{[1,2]}$

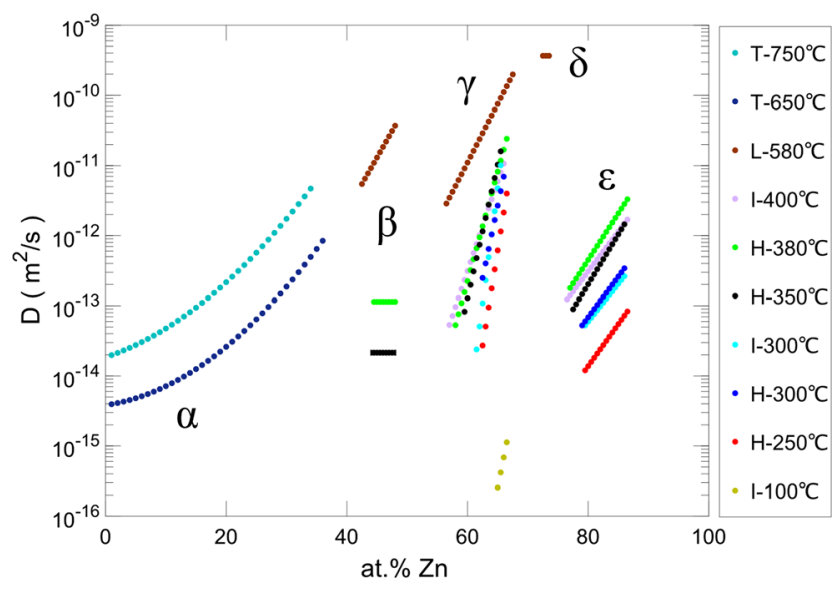

Fig. 12 A comprehensive overview of all interdiffusion coefficients at various temperatures across the entire compositional range from the present study and results from re-analyzing the diffusion profiles from Hoxha et al. Hoxha et al.'s results are extracted from composition profiles of diffusion couples underwent the 32-h heat treatments. ${ }^{[15]}$ T: transient liquid phase diffusion couples; L: Liquid-solid diffusion couples; H: FSA of Hoxha et al's diffusion profiles; and I: Infinite (pure to pure) $\mathrm{Cu}-\mathrm{Zn}$ diffusion couples

hcp $\eta$ - Zn phase, it is a good assumption that interdiffusion coefficients are the same as the impurity diffusion coefficients.

Figure 12 summarizes all the interdiffusion coefficients obtained from the current study, including the results by

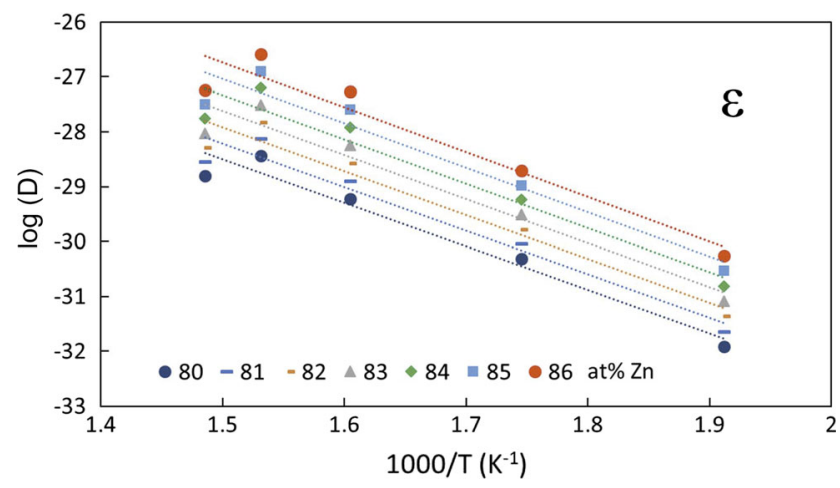

Fig. 13 Interdiffusion coefficients of the $\varepsilon$ intermetallic phase at compositions between 80 and 86 at.\% $\mathrm{Zn}$ plotted against inverse temperature. The fitted line represents the Arrhenius relationship for each specific composition

performing FSA on the composition profiles provided by Hoxha et al. The diffusion coefficients provided for diffusion couples that were investigated by Hoxha et al. are those from the 32-h heat treatment performed at each temperature (the longest heat treatment). The diffusion coefficients for the fcc $\alpha$-Cu and hcp $\eta$-Zn phases were not included in this figure for temperatures below $650{ }^{\circ} \mathrm{C}$ due to the insufficient resolution of EPMA in obtaining reliable composition profiles from these thin phases, as was explained before.

The general trends of the interdiffusion coefficients from the fcc $\alpha-\mathrm{Cu}, \gamma$ intermetallic, and $\varepsilon$ intermetallic phases are consistent across multiple temperatures (Fig. 7-12). Although the diffusion coefficients extracted from the present experimental study are, on average, slightly lower than those extracted from the diffusion concentration profiles provided by Hoxha et al., the overall results from the two studies agree well. For instance, the interdiffusion coefficients from pure to pure $\mathrm{Cu}-\mathrm{Zn}$ diffusion couples diffusion annealed at $300{ }^{\circ} \mathrm{C}$ are consistent with those extracted from Hoxha et al.'s concentration profiles at the same temperature for both the $\gamma$ and $\varepsilon$ intermetallic phases. Several experimental variables could have contributed to the slight differences in results between the two studies such as sample preparation and encapsulation and heat treatment temperature accuracy.

\section{Activation Energies and Prefactors}

The extracted interdiffusion coefficients from the $\beta, \gamma$ and $\varepsilon$ phases were plotted against the inverse of temperature for individual compositions, as shown in Fig. 13 for the $\varepsilon$ phase. The fitted line represents the Arrhenius relationship between diffusion coefficients and temperature. From this relationship, the activation energy for diffusion, Q, and pre- 

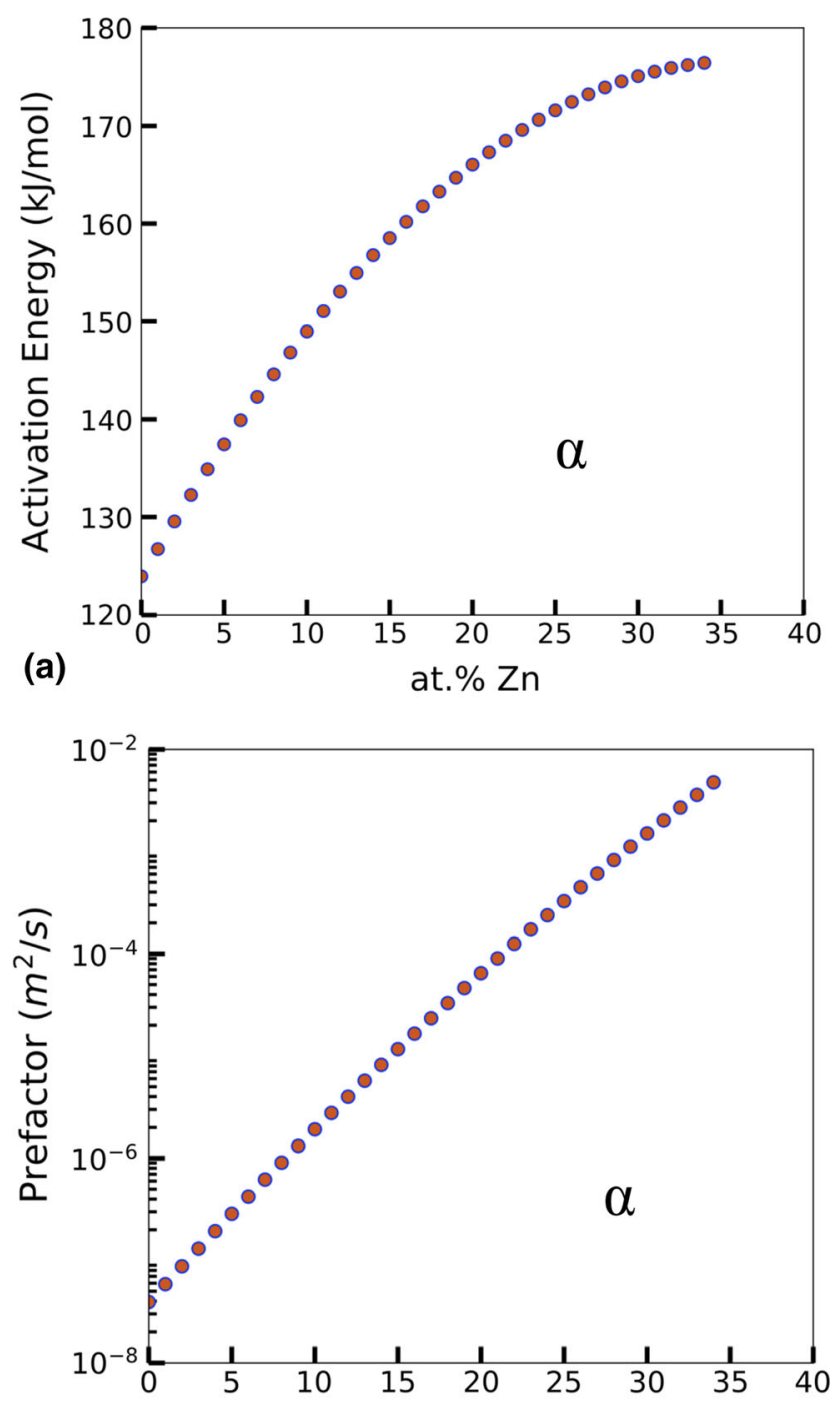

(b)

at. $\% \mathrm{Zn}$

Fig. 14 Activation energy and Arrhenius prefactor of the fcc $\alpha-\mathrm{Cu}$ solid solution phase as a function of composition

exponential factor, or Arrhenius prefactor, $\mathrm{D}_{0}$, can be calculated for the phase at a specific composition.

Activation energies for diffusion and Arrhenius prefactors were calculated for the fcc $\alpha-\mathrm{Cu}, \beta, \gamma$, and $\varepsilon$ phases. As these values vary with composition, the same process was performed every 1 at. $\%$ for the fcc $\alpha$-Cu solid solution phase and the $\beta, \gamma$, and $\varepsilon$ intermetallic phases (Fig. 14 and 15). The activation energy and Arrhenius prefactor for the hcp $\eta$ - Zn phase based on impurity diffusion coefficient measurements from Batra and Huntington are $124.6 \mathrm{~kJ} / \mathrm{mol}$ and $2 \times 10^{-4} \mathrm{~m}^{2} / \mathrm{s} .{ }^{[2]}$ The activation energy of the high temperature intermetallic $\delta$ phase could not be calculated since the diffusion coefficient was only calculated for the $580{ }^{\circ} \mathrm{C}$ heat treatment. Trendlines were added to the activation energies and Arrhenius prefactors for the $\beta, \gamma$, and $\varepsilon$ phases. The activation energies and Arrhenius prefactors

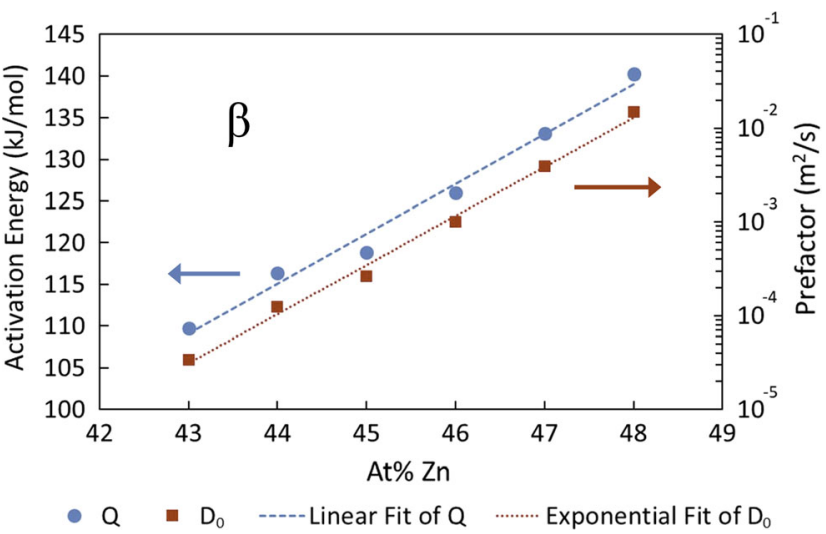

Fig. 15 Activation energy and Arrhenius prefactor of the $\beta$ intermetallic phase as a function of composition

for the $\alpha-\mathrm{Cu}, \beta$, and $\varepsilon$ phases all increased with increasing $\mathrm{Zn}$ content, whereas the values decreased for the $\gamma$ phase.

The fitted lines in Fig. 14-17 are summarized in Table 3. The equations allow one to compute the interdiffusion coefficients of each phase (except for the $\delta$ phase) at a given composition and temperature. The equations represent our best interpretation and compromise to reach consistent overall assessments of the interdiffusion coefficients of the phases (except for the $\delta$ phase) for the $\mathrm{Cu}-\mathrm{Zn}$ binary system. They also represent the most comprehensive collection/review of all the available experimental data, including new data obtained from the current study.

\section{Discussion}

As observed in the experiments, the maximum $\mathrm{Zn}$ concentrations in the fcc $\alpha$-Cu phase at temperatures $\leq 580{ }^{\circ} \mathrm{C}$ were significantly below the solubility values in the binary $\mathrm{Cu}-\mathrm{Zn}$ phase diagram, as shown in Sect. 3. One explanation is that the fcc $\alpha-\mathrm{Cu}$ phase formed at those lower temperatures are extremely thin as a results of extremely low diffusion coefficients, leading to very step gradients that cannot be resolved using EPMA with a resolution on the order of $1 \mu \mathrm{m}$. Chen and Zhao had investigated such steep gradient phenomenon and concluded that diffusion coefficients extracted from EPMA concentration profiles with gradients greater than 1 at. $\%$ per micron are unreliable. ${ }^{[30]}$

Both the impurity and interdiffusion coefficients at low temperatures for the fcc $\alpha$-Cu phase were estimated in the following fashion: (a) the recommended Arrhenius equation of the impurity diffusion coefficients of $\mathrm{Zn}$ in pure $\mathrm{Cu}$ from the literature ${ }^{[6,8,31]}$ were employed to compute the impurity diffusion coefficients at low temperatures, Fig. 18(a), which set the vertical locations of the interdiffusion coefficient curves in Fig. 18(b); (2) a polynomial 
Table 3 The fitted equations based on the lines in Fig. 16-19 have the capabilities to compute the interdiffusion coefficients of each of the phases (except for the $\delta$ phase) at a given composition and temperature

\begin{tabular}{lllc}
\hline Phase & \multicolumn{1}{c}{ Pre-factor $\mathrm{D}_{0}\left(\mathrm{~m}^{2} / \mathrm{s}\right)$} & \multicolumn{1}{c}{ Activation Energy Q $(\mathrm{J} / \mathrm{mol})$} & Temperature $\left({ }^{\circ} \mathrm{C}\right)$ \\
\hline$\alpha-\mathrm{Cu}$ & $4 \times 10^{-8} \exp ^{\left(-18.62 X_{Z n}^{2}+40.73 X_{Z n}\right)}$ & $410510 X_{Z n}^{2}+290970 X_{Z n}-123900$ & $650-750$ \\
$\beta$ & $1 \times 10^{-27} \exp ^{120.42 X_{Z n}}$ & $600180 X_{Z n}-149020$ & $350-580$ \\
$\gamma$ & $1 \times 10^{13} \exp ^{-71.55 X_{Z n}}$ & $-774080 X_{Z n}+553820$ & $250-580$ \\
$\varepsilon$ & $3 \times 10^{-20} \exp ^{35.34 X_{Z n}}$ & $32880 X_{Z n}+39570$ & $250-400$ \\
$\eta-Z n *$ & $2 \times 10^{-4}$ & 124580 & $338-415^{[2]}$ \\
\hline
\end{tabular}

Both the pre-factor $\mathrm{D}_{0}$ and the activation energy $\mathrm{Q}$ are a function of composition

where $R=8.134$ is the gas constant in unit of $\mathrm{J} / \mathrm{mol}-\mathrm{K}, T$ is in Kelvin, and $X_{Z n}$ is the mole fraction of $\mathrm{Zn} . D^{*}$ for the $\eta$ - Zn phase is the impurity diffusivity of $\mathrm{Cu}$ in hcp $\mathrm{Zn}$ and thus only dependent on temperature

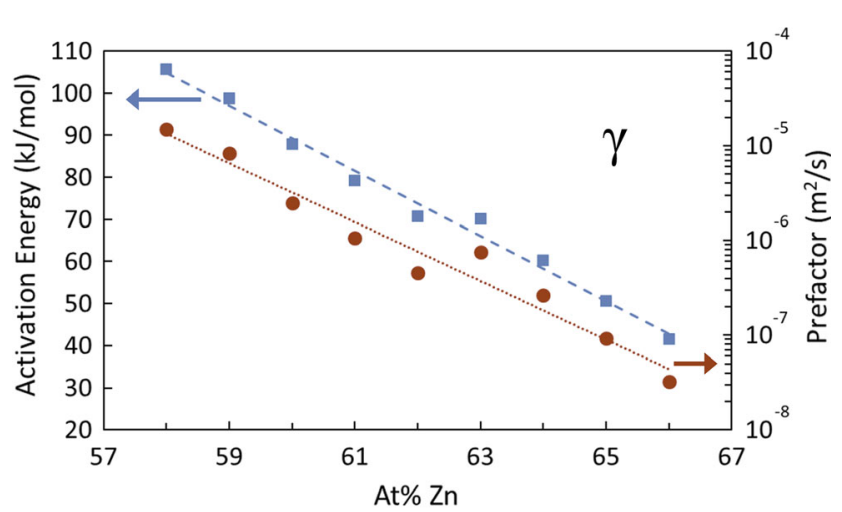

- $\mathrm{Q} \quad \mathrm{D}_{0} \quad---$ Linear Fit of $\mathrm{Q} \quad \cdots \cdots . .$. Exponential Fit of $\mathrm{D}_{0}$

Fig. 16 Activation energy and Arrhenius prefactor of the $\gamma$ intermetallic phase as a function of composition

was fitted to match the consistent shape of the compositiondependent interdiffusion coefficients at high temperatures where experimental interdiffusion data are available; (3) the same constants in the polynomial (which define the shape of the interdiffusion coefficient - composition curves) were used to compute the interdiffusion coefficients of the $\alpha-\mathrm{Cu}$ phase at low temperatures, Fig. 18(b). In other words, the consistent trend of the interdiffusion coefficients was assumed for low temperatures with the vertical locations of the interdiffusion coefficient curves being systematically moved based on the independently measured and reliable impurity diffusion data of $\mathrm{Zn}$ in $\alpha$ $\mathrm{Cu}$.

With the estimated interdiffusion coefficients for the $\alpha$ $\mathrm{Cu}$ phase from Fig. 18(b) and other diffusion coefficients evaluated from the current study for the other phases, the FSA code was employed to simulate the composition profiles at the experimental temperatures to be compared with some of the experimental concentration composition profiles. Excellent agreement was evident in Fig. 19. The simulations resulted in a thickness of $<2 \mu \mathrm{m}$, most of them $<1 \mu \mathrm{m}$, for the $\alpha$-Cu phase for all the diffusion heat

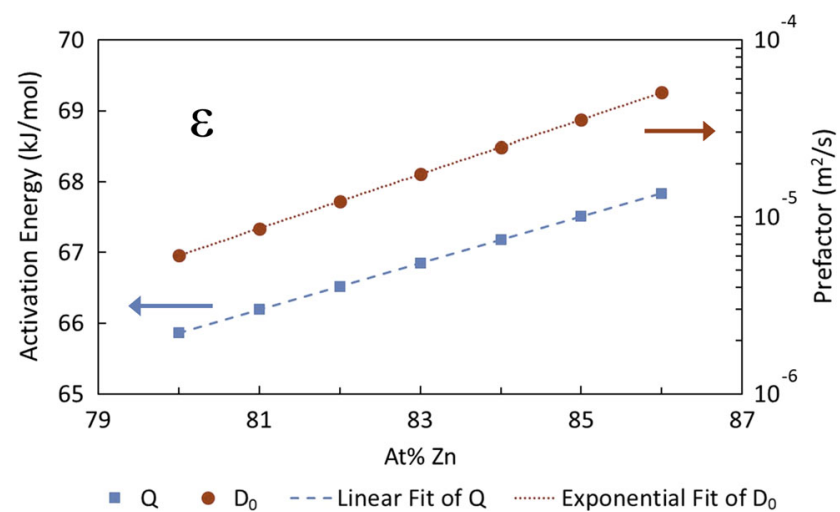

Fig. 17 Activation energy and Arrhenius prefactor of the $\varepsilon$ intermetallic phase as a function of composition

treatments $\leq 400{ }^{\circ} \mathrm{C}$. The composition variation from $\sim$ 33 to 35 at. $\%$ (solubility values) to 0 at. $\%$ in the $\alpha-\mathrm{Cu}$ phase within $<1 \mu \mathrm{m}$ could not be measured using EPMA. This extremely steep concentration gradient, beyond the spatial resolution of EPMA, explains the appearance that the measured $\mathrm{Zn}$ content in the $\alpha$-Cu phase is significantly lower than the solubility limits in the phase diagram shown in Fig. 1.

\section{Conclusion}

The diffusion behavior and phase equilibria in the $\mathrm{Cu}-\mathrm{Zn}$ binary system were investigated using solid-solid and solid-liquid diffusion couples that were annealed at temperatures ranging from 100 to $750{ }^{\circ} \mathrm{C}$ for various durations as summarized in Table 1. EPMA was employed to obtain diffusion/concentration profiles from those diffusion couples in order to collect the phase diagram information (Fig. 1 and Table 2) by assuming local equilibrium at the phase interfaces. Some modifications of the binary phase diagram based on the new experimental data are recommended and summarized in Fig. 1. The composition range of the $\gamma$ intermetallic phase narrows significantly with 

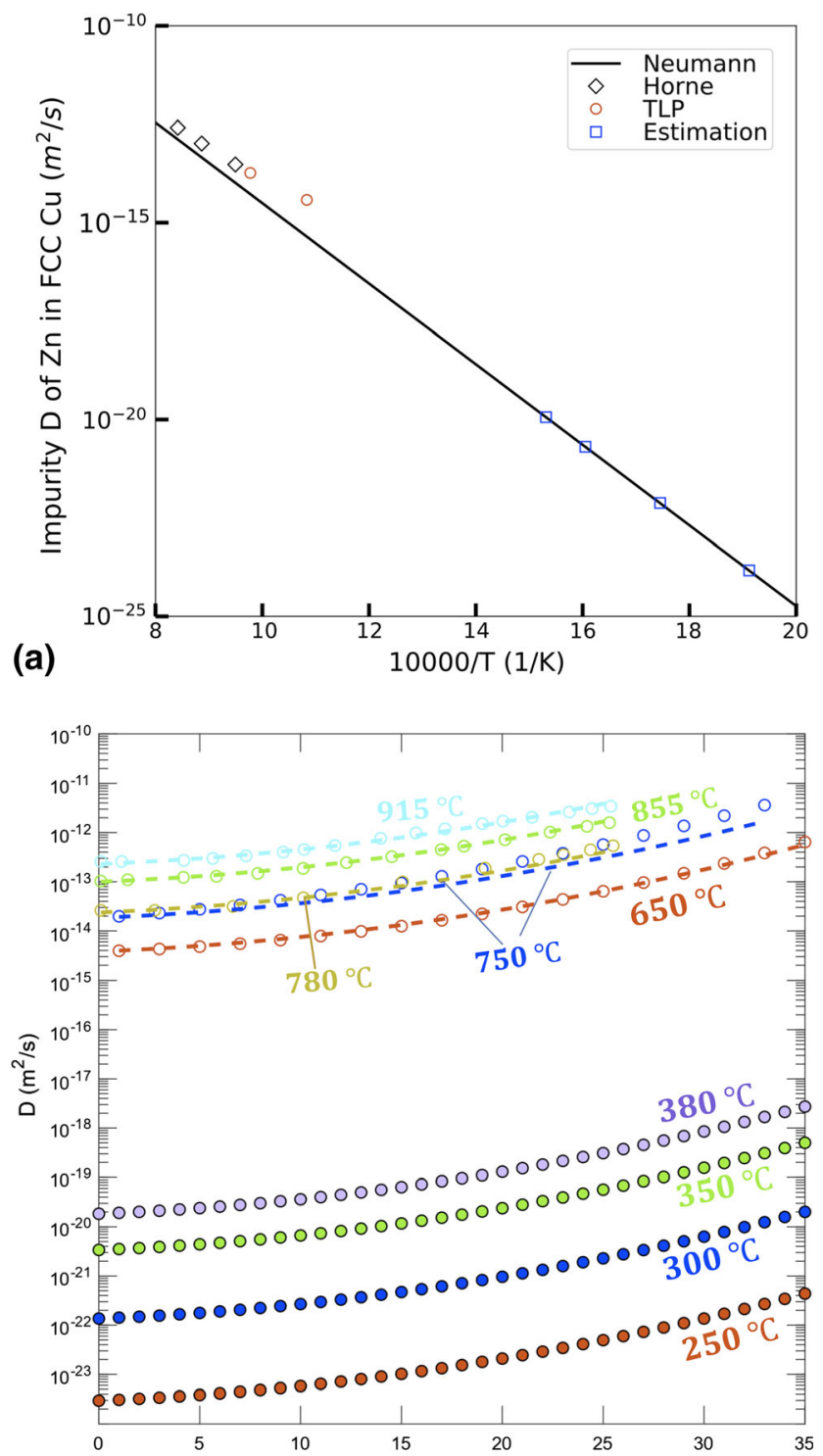

(b)

at. $\% \mathrm{Zn}$

Fig. 18 (a) Estimated impurity diffusion coefficients at 250, 300, 350 , and $380{ }^{\circ} \mathrm{C}$ [Blue diamonds at lower right part of (a)] using the recommended Arrhenius equation (straight line) assessed from experimental results by Neumann and Tuijn ${ }^{[1]}$; and (b) Interdiffusion coefficients of the fcc $\alpha$-Cu phase at a wide range of temperatures calculated using the impurity diffusion coefficients of $\mathrm{Zn}$ in $\mathrm{Cu}$ from (a) which set the curve locations at pure $\mathrm{Cu}(0$ at. $\% \mathrm{Zn})$ and a constant polynomial function fitted from the high-temperature interdiffusion data $^{[3,10]}$

decreasing temperature, which should be taken into account in future phase diagram and thermodynamic assessments.

In addition to phase diagram information, a robust forward simulation analysis (FSA) was applied to various solid-solid and solid-liquid diffusion profiles to obtain the interdiffusion coefficients at various temperatures for three intermetallic phases $(\beta, \gamma$ and $\varepsilon)$ and the fcc $\alpha$-Cu solid

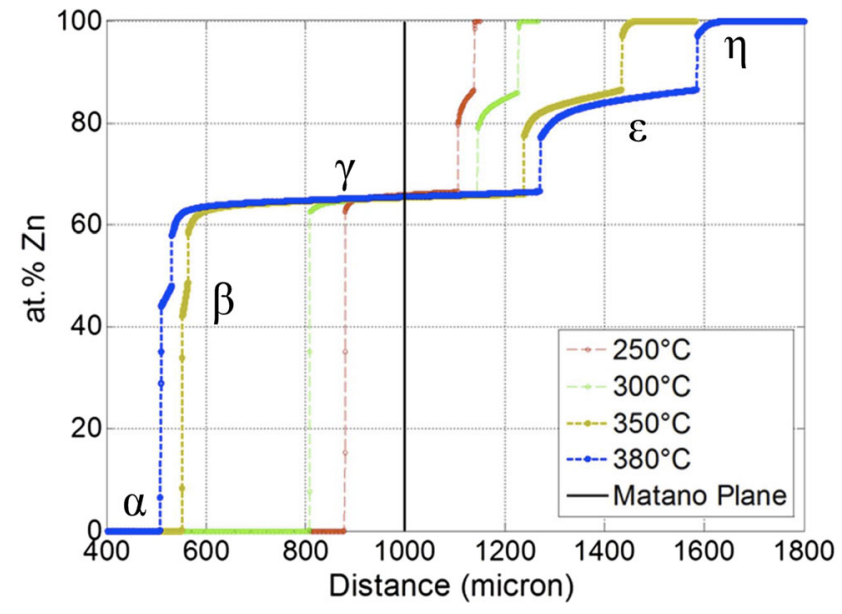

Fig. 19 Simulated composition profiles at the low temperatures (all for $32 \mathrm{~h}$ ) in comparison with the experimental data obtained using EPMA by Hoxha et al

solution phase. The composition profiles from Hoxha et al. were also re-analyzed using FSA to obtain more reliable diffusion coefficient data without the assumption of constant diffusion coefficients for the intermetallic phases. The interdiffusion coefficients of both the $\gamma$ and $\varepsilon$ intermetallic phases are very strongly composition-dependent and increase significantly with increasing $\mathrm{Zn}$ concentration in the phases. Such a strong composition dependency of interdiffusion coefficients is usually a good indication of the formation of high concentrations of point defects in the high diffusion coefficient compositions of the phases.

A comprehensive assessment of the interdiffusion coefficients in three intermetallic phases $\beta, \gamma$ and $\varepsilon$ was performed and summarized in Fig. 8-10. Activation energies and Arrhenius pre-factors were evaluated for each phase as a function of composition. The fitted equations based on the lines in Fig. 13-17, summarized in Table 3, have the capabilities of computing the interdiffusion coefficients of each of the phase (except for the $\delta$ phase) at a given composition and temperature.

A clear explanation is provided for the puzzling low $\mathrm{Zn}$ concentrations often observed in the $\mathrm{Cu}$-rich fcc phase of $\mathrm{Cu}-\mathrm{Zn}$ diffusion couples at low temperatures in comparison with the expected high solubility values based on the equilibrium $\mathrm{Cu}-\mathrm{Zn}$ phase diagram. The extremely low diffusion coefficients in this phase at low temperatures lead to extremely steep concentration variation from $\sim 33-35$ at. $\%$ (solubility values) to 0 at. $\%$ in the $\alpha-\mathrm{Cu}$ phase within $<1 \mu \mathrm{m}$, which could not be measured using EPMA. This extremely steep concentration gradient is beyond the spatial resolution of EPMA.

Acknowledgments The authors would like to thank Dr. Hoxha for generously providing original digital EPMA composition profiles for $\mathrm{Cu}-\mathrm{Zn}$ diffusion couples annealed at various temperatures. The 
authors also greatly appreciate John Kuper for his assistance with the experiments. This study was supported by the internal funds of The Ohio State University with part of Dr. Qiaofu Zhang's time supported by the National Science Foundation (NSF) under Grant Number NSFDMR-1237577. Prof. J.-C. Zhao's time was partially supported by NSF Grant Numbers NSF-DMR-1237577 and NSF-DMR-1904245.

\section{References}

1. G. Neumann and C. Tuijn, Self-Diffusion and Impurity Diffusion in Pure Metals: Handbook of Experimental Data, Elsevier, Amsterdam, 2011

2. A.P. Batra and H.B. Huntington, Diffusion of Copper and Gallium in Single Crystals of Zinc, Phys. Rev., 1966, 145, p 542-546. https://doi.org/10.1103/PhysRev.145.542

3. Y. Funamizu and K. Watanabe, Interdiffusion of $\beta$ and $\beta$ ' phases in the Cu-Zn system, J. Jpn. Inst. Met., 1975, 39, p 1087-1092. https://doi.org/10.2320/jinstmet1952.39.10_1087

4. Y. Funamizu and K. Watanabe, Interdiffusion in the $\varepsilon$ Phase of the Cu-Zn System, Trans. Jpn. Inst. Met., 1976, 17, p 59-60. https://doi.org/10.2320/matertrans1960.17.59

5. O.B. Sørensen and E. Maahn, The Reaction Between Copper and Liquid Zinc, Met. Sci., 1976, 10, p 385-390. https://doi.org/10. 1080/03063453.1976.11683561

6. J. Hino, C. Tomizuka, and C. Wert, Internal Friction and Diffusion in 31\% Alpha Brass, Acta Metall., 1957, 5, p 41-49. https:// doi.org/10.1016/0001-6160(57)90153-0

7. G.E. Murch and C.M. Bruff, Diffusion in Solid Metals and Alloys, Springer, Berlin, 1990, https://doi.org/10.1007/b37801

8. N.L. Peterson and S.J. Rothman, Diffusion and Correlation Effects in Copper-Zinc Alloys, Phys. Rev. B., 1970, 2, p 1540-1547. https://doi.org/10.1103/PhysRevB.2.1540

9. A.B. Kuper, D. Lazarus, J.R. Manning, and C.T. Tomizuka, Diffusion in Ordered and Disordered Copper-Zinc, Phys. Rev., 1956, 104, p 1536-1541. https://doi.org/10.1103/PhysRev.104. 1536

10. R.W. Balluffi and L.L. Seigle, Diffusion in Bimetal Vapor-Solid Couples, J. Appl. Phys., 1954, 25, p 607-614. https://doi.org/10. $1063 / 1.1721698$

11. G.T. Horne and R.F. Mehl, Mobilities in Diffusion in Alpha Brass, Trans. Am. Inst. Mining, Metall. Pet. Eng., 1955, 203, p 88-99

12. Y.E. Ugaste, Concentration Dependence of the Coefficient of Mutual Diffusion in Phases of a Copper-Zinc System, Fiz. Met. Metalloved., 1969, 27, p 663

13. Y.E. Ugaste and V.N. Pimenov, Interdiffusion in Ordered Beta Brass, Phys. Met. Metallogr., 1971, 31 (2), p 140 [Original Russian: Fiz. Met. Metalloved., 1971, 31 (2), p 363].

14. A.P. Miodownik, $\mathrm{Cu}-\mathrm{Zn}$ (Copper-Zinc), in: T.B. Massalski (Ed.), Binary Alloy Phase Diagrams, 2nd Ed., Vol II, 1990: p 1508-1510, ASM International, Materials Park, Ohio

15. A. Hoxha, H. Oettel, and D. Heger, Calculation of the Interdiffusion Coefficient in the $\mathrm{Cu}-\mathrm{Zn}$ Diffusion Couple, AIP Conf. Proc., 2010, 1203, p 591-595. https://doi.org/10.1063/1.3322515

16. A. Hoxha and J. Jani, The Diffusion Coefficients of $\mathrm{Cu}$ And $\mathrm{Zn} \mathrm{In}$ $\alpha$ - And H- Solid Solutions, Int. J. Sci. Technol. Res., 2015, 4, p 173-176

17. ASM Alloy Phase Diagram Database, (2020). https://matdata. asminternational.org/apd/.
18. Q. Zhang and J.C. Zhao, Extracting Interdiffusion Coefficients from Binary Diffusion Couples Using Traditional Methods and a Forward-Simulation Method, Intermetallics, 2013, 34, p 132-141. https://doi.org/10.1016/j.intermet.2012.11.012

19. M.E. Glicksman, Diffusion in Solids: Field Theory, Solid-State Principles, and Applications, Wiley, New Jersey, 2000

20. F. Sauer and V. Freise, Diffusion in Binaren Gemischen mit Volumenanderung, Z. Für Elektrochem., 1962, 66, p 353-362. https://doi.org/10.1002/BBPC.19620660412

21. C. Wagner, The Evaluation of Data Obtained with Diffusion Couples of Binary Single-Phase and Multiphase Systems, Acta Metall., 1969, 17, p 99-107. https://doi.org/10.1016/00016160(69)90131-X

22. Q. Zhang and J.C. Zhao, Impurity and Interdiffusion Coefficients of the $\mathrm{Cr}-\mathrm{X}(\mathrm{X}=\mathrm{Co}, \mathrm{Fe}, \mathrm{Mo}, \mathrm{Nb}, \mathrm{Ni}, \mathrm{Pd}, \mathrm{Pt}, \mathrm{Ta})$ Binary Systems, J. Alloys Compd., 2014, 604, p 142-150. https://doi.org/10.1016/ j.jallcom.2014.03.092

23. Q. Zhang, Z. Chen, W. Zhong, and J.-C. Zhao, Accurate and Efficient Measurement of Impurity (Dilute) Diffusion Coefficients Without Isotope Tracer Experiments, Scr. Mater., 2017, 128, p 32-35. https://doi.org/10.1016/j.scriptamat.2016.09.040

24. Z. Chen, Z.-K. Liu, and J.-C. Zhao, Experimental Determination of Impurity and Interdiffusion Coefficients in Seven $\mathrm{Ti}$ and $\mathrm{Zr}$ Binary Systems Using Diffusion Multiples, Metall. Mater. Trans. A, 2018, 49, p 3108-3116. https://doi.org/10.1007/s11661-0184645-9

25. W. Zhong and J.-C. Zhao, First Reliable Diffusion Coefficients for Mg-Y and Additional Reliable Diffusion Coefficients for MgSn and Mg-Zn, Metall. Mater. Trans. A, 2017, 48, p 5778-5782. https://doi.org/10.1007/s11661-017-4378-1

26. S. Vivès, P. Bellanger, S. Gorsse, C. Wei, Q. Zhang, and J.-C. Zhao, Combinatorial Approach Based on Interdiffusion Experiments for the Design of Thermoelectrics: Application to the Mg2(Si, Sn) Alloys, Chem. Mater., 2014, 26, p 4334-4337. https://doi.org/10.1021/cm502413t

27. L. Zhu, Q. Zhang, Z. Chen, C. Wei, G.M. Cai, L. Jiang, Z. Jin, and J.-C. Zhao, Measurement of Interdiffusion and Impurity Diffusion Coefficients in the bcc Phase of the Ti-X (X = Cr, Hf, Mo, Nb, V, Zr) Binary Systems Using Diffusion Multiples, $J$. Mater. Sci., 2017, 52, p 3255-3268. https://doi.org/10.1007/ s10853-016-0614-0

28. W. Zhong and J.-C. Zhao, First Experimental Measurement of Calcium Diffusion in Magnesium Using Novel Liquid-Solid Diffusion Couples and Forward-Simulation Analysis, Scr. Mater., 2017, 127, p 92-96. https://doi.org/10.1016/j.scriptamat.2016.09. 008

29. Z. Chen, Q. Zhang, and J.-C. Zhao, pydiffusion: A Python Library for Diffusion Simulation and Data Analysis, J. Open Res. Softw., 2019, 7, p 13. https://doi.org/10.5334/jors.255

30. G. Nandipati, N. Govind, A. Andersen, and A. Rohatgi, Selflearning Kinetic Monte Carlo Simulations of Al Diffusion in $\mathrm{Mg}$, J. Phys. Condens. Matter, 2016, 28, p 155001. https://doi.org/10. 1088/0953-8984/28/15/155001

31. S.M. Klotsman, Y.A. Rabovskiy, V.K. Talinskiy, and A.N. Timofeyev, Diffusion of Impurities in Polycrystalline Copper. I. Diffusion of Zinc, Fiz. Met. i Metalloved., 1969, 28, p 1025-1028

Publisher's Note Springer Nature remains neutral with regard to jurisdictional claims in published maps and institutional affiliations. 